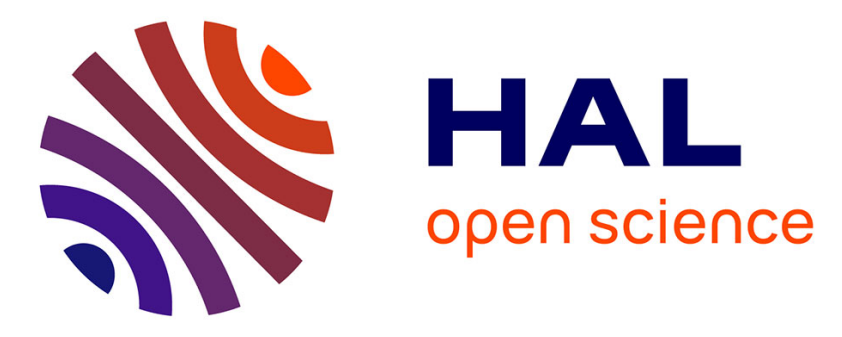

\title{
Development of small CO2 gas measurements with AixMICADAS
}

Thibaut Tuna, Yoann Fagault, Lise Bonvalot, Manuela Capano, Edouard Bard

\section{To cite this version:}

Thibaut Tuna, Yoann Fagault, Lise Bonvalot, Manuela Capano, Edouard Bard. Development of small $\mathrm{CO} 2$ gas measurements with AixMICADAS. Nuclear Instruments and Methods in Physics Research Section B: Beam Interactions with Materials and Atoms, 2018, 437, pp.93-97. 10.1016/j.nimb.2018.09.012 . hal-02078496

\section{HAL Id: hal-02078496 https://hal.science/hal-02078496}

Submitted on 24 Apr 2019

HAL is a multi-disciplinary open access archive for the deposit and dissemination of scientific research documents, whether they are published or not. The documents may come from teaching and research institutions in France or abroad, or from public or private research centers.
L'archive ouverte pluridisciplinaire HAL, est destinée au dépôt et à la diffusion de documents scientifiques de niveau recherche, publiés ou non, émanant des établissements d'enseignement et de recherche français ou étrangers, des laboratoires publics ou privés. 


\title{
Development of small $\mathrm{CO}_{2}$ gas measurements with AixMICADAS
}

\author{
Thibaut Tuna*, Yoann Fagault, Lise Bonvalot, Manuela Capano, Edouard Bard* \\ CEREGE, Aix-Marseille University, CNRS, IRD, INRA, Collège de France, Technopôle de l'Arbois, BP 80, 13545 Aix-en-Provence, France
}

A R T I C L E I N F O

\section{Keywords:}

AMS

Radiocarbon

Gas ion source

Small samples

\begin{abstract}
A B S T R A C T
After three years of tests and developments, the performances of the AixMICADAS facility have been established for small $\mathrm{CO}_{2}$ samples with a carbon mass inferior to $100 \mu \mathrm{g}$. The instrument shows very good stability and reliability when measuring small samples with its gas ion source. In this configuration, the precision is mainly limited by counting statistics and also the accuracy by contamination effects for the smallest samples $(<20 \mu \mathrm{gC})$. A long term variability of 7-8\% is evaluated with $80-100 \mu g$ C NIST oxalic acid 2 samples and modern carbonate samples. Our pretreatment and analytical protocols allow for very low blank levels corresponding to ${ }^{14} \mathrm{C}$ ages of 53,000 years BP and 48,000 years BP for carbonate samples and organic materials, respectively.
\end{abstract}

\section{Introduction}

AixMICADAS [1] is a new AMS facility used to date paleoclimatic records and to study natural and anthropogenic exchanges of carbon between the atmosphere, the oceans, the biosphere and soils by using radiocarbon as a tracer. Installed in April 2014 in Aix-en-Provence (France) at the CEREGE laboratory, the facility has so far been used to measure more than $2600 \mathrm{CO}_{2}$ gas samples and 2300 solid graphite samples. These were measured over three years to develop and test the performances of our protocol for various samples.

Thanks to its gas interface system (GIS, [2]) AixMICADAS allows the analysis of small $\mathrm{CO}_{2}$ samples $(<100 \mu \mathrm{gC})$ from carbonates (by acidification with the carbonate handling system, CHS), aerosols, collagen and other molecular compounds (by combustion with an elemental analyzer, EA), molecular compounds and in situ ${ }^{14} \mathrm{C}\left(\mathrm{CO}_{2}\right.$ sealed in closed ampoules) with no need of a graphitization step. Carbonate samples hydrolyzed with the CHS represent almost $50 \%$ of the $\mathrm{CO}_{2}$ gas samples measured so far with AixMICADAS (see companion paper by Fagault et al. in this NIMB issue). Precision, accuracy and residual contaminations have been thoroughly studied, as reported below (all ${ }^{14} \mathrm{C}$ data are reported as conventional ages or $\mathrm{F}^{14} \mathrm{C}$ following $[3,4]$ ). After a short description of the instrument and the protocols used to measure small gas samples, this paper will report the performances of the AixMICADAS instrument which have been evaluated after three years of operation.

\section{Setup and measurements}

AixMICADAS is an updated version of the original compact AMS system developed by the ETH in Zürich [5]. With its gas ion source interface system, it allows ${ }^{14} \mathrm{C}$ measurement of $\mathrm{CO}_{2}$ directly for both ultra-small samples and standard mass samples with high stability and reproducibility $[6,7]$. The design of the MICADAS instrument has been described in detail in various articles $[1,5]$.

The $\mathrm{C}^{-}$beam is produced inside the Cs sputtering ion source with an extraction energy of $40 \mathrm{keV}$. The low energy $90^{\circ}$ magnet associated with the fast beam pulsing system sequentially injects the three isotopes ${ }^{12} \mathrm{C}(30 \mu \mathrm{s}),{ }^{13} \mathrm{C}(520 \mu \mathrm{s})$ and ${ }^{14} \mathrm{C}(40 \mathrm{~ms})$ into the tandem accelerator unit. An offset ${ }^{12} \mathrm{C}^{-}$Faraday cup is placed just after the LE magnet to monitor the low energy current. The acceleration voltage of AixMICADAS is typically set to a value of $193.6 \mathrm{kV}$ and the stripping with helium ensures an overall transmission for ${ }^{12} \mathrm{C}$ of $48.1 \pm 0.6 \%$ for all measured gas samples $\left({ }^{12} \mathrm{C}^{-}\right.$current $\left.<20 \mu \mathrm{A}\right)$. Faraday cups are located in the focal plane of the high-energy magnet to measure ion beam currents of ${ }^{12} \mathrm{C}^{+},{ }^{13} \mathrm{C}(\mathrm{H}){ }^{+}$and ${ }^{13} \mathrm{C}^{+}$, where ${ }^{13} \mathrm{C}(\mathrm{H})^{+}$represents ${ }^{13} \mathrm{C}^{+}$ions fragmented from the ${ }^{13} \mathrm{CH}^{-}$beam that is injected along with ${ }^{14} \mathrm{C}^{-}$. The ${ }^{13} \mathrm{C}(\mathrm{H})^{+}$Faraday cup is used to monitor the contribution of molecules that interfere with ${ }^{14} \mathrm{C}$ measurement $[5,6]$. Finally, a $90^{\circ}$ electrostatic deflector energy filter is used just before the ion gas detector which is itself isolated from the vacuum of the accelerator by a $5 \mathrm{~mm} \times 5 \mathrm{~mm}$ nitride silicon window of thickness $50 \mathrm{~nm}$ [8]. BATS software is used for data reduction [9]. The optimal parameters of the ion source in gas configuration are given in Table 1, where they are compared with those used in solid configuration.

Three devices providing $\mathrm{CO}_{2}$ for the ion source are connected to the gas interface system (GIS): a cracker for $\mathrm{CO}_{2}$ sealed in glass ampoules, an elemental analyzer (EA) and a carbonate hydrolysis system (CHS) $[10,11]$. We have previously described the configuration of our EA coupled to the GIS [12]. The main characteristic of the EA is that it

\footnotetext{
* Corresponding authors.

E-mail addresses: tuna@cerege.fr (T. Tuna), bard@cerege.fr (E. Bard).
} 
Table 1

Main operation parameters of the AixMICADAS system in gas and solid configurations. ${ }^{a}$ When the sample mass is higher than $30 \mu \mathrm{gC} .{ }^{\mathrm{b}}$ For standard precision measurement. ${ }^{\mathrm{C}}$ For high precision measurement.

\begin{tabular}{lll}
\hline Parameter & Value (gas configuration) & $\begin{array}{l}\text { Value (solid } \\
\text { configuration) }\end{array}$ \\
\hline Typical ${ }^{12} \mathrm{C}^{-}$current & $5-15 \mu \mathrm{A}$ & $50-70 \mu \mathrm{A}$ \\
Cesium temperature & $160^{\circ} \mathrm{C}$ & $147^{\circ} \mathrm{C}$ \\
Sample mass range & $5-120 \mu \mathrm{C}$ & $0.3-1 \mathrm{mgC}$ \\
Transmission & $48.1 \pm 0.6 \%$ & $47.0 \pm 0.8 \%$ \\
Injection pressure & $1300 \mathrm{mbar}\left(5 \% \mathrm{CO}_{2}\right.$ in & - \\
& $\mathrm{He})$ & - \\
Injection flow & $2.80 \mu g \mathrm{gC} \min ^{-1}$ & $30^{\mathrm{b}} / 60^{\mathrm{c}} \mathrm{min}$ \\
Measurement time & $12 \mathrm{~min}^{\mathrm{a}}$ & $3-4 \% 0^{\mathrm{b}} / 2 \% \mathrm{c}^{\mathrm{c}}$ \\
Typical precision & $6-7 \% 0^{\mathrm{a}}$ & \\
$\quad$ & & \\
\hline
\end{tabular}

works with a combustion tube filled with tungsten oxide heated to $1050^{\circ} \mathrm{C}$ to allow the introduction of silver boats. We have tested different metals (Al, Sn, Ag), boat sizes, and cleaning protocols. Optimal blanks are obtained with $\mathrm{Ag}$ cups that are baked at $800^{\circ} \mathrm{C}$ for $2 \mathrm{~h}$ to eliminate organic contamination.

Carbonates are processed with the CHS following a leaching procedure where $30 \%$ of the initial $\mathrm{CaCO}_{3}$ mass is removed with hydrochloric acid $(\mathrm{HCl})$ prior to the full hydrolysis of the remaining mass with phosphoric acid $\left(\mathrm{H}_{3} \mathrm{PO}_{4} 85 \%\right)$. The CHS device and the pretreatment protocol for various carbonates are described in detail in a companion paper [21].

The $\mathrm{CO}_{2}$ produced by both EA or CHS is captured in the zeolite trap inside the GIS [2]. The $\mathrm{CO}_{2}$ is then released by heating the zeolite trap to $450{ }^{\circ} \mathrm{C}$ and is mixed inside the syringe with a helium flow in order to obtain $5 \% \mathrm{CO}_{2}$ in the gas mixture, which will be fed into the ion source.

In parallel, two cylinders of gas standards are connected to the GIS in order to monitor the blank $\left(5 \%{ }^{14} \mathrm{C}\right.$-dead $\mathrm{CO}_{2}$ and $95 \%$ He provided by Linde Gas) and oxalic acid $2\left(4.5 \% \mathrm{CO}_{2}\right.$ from NIST $4990 \mathrm{C}$ OxA2 and $95.5 \%$ helium - bottle provided by IonPlus AG) used to perform the measurement normalizations.

The $\mathrm{CO}_{2}$ is injected from the GIS into the ion source through a small fused silica capillary (SGE analytics ID $=0.060 \mathrm{~mm}$; OD $=0.220 \mathrm{~mm}$; methyl deactivated; $90 \mathrm{~cm}$ length) continuously fed by the syringe which is driven by a stepping motor controlled by the GIS software. The carbon flow is software controlled and is set to $2.80 \mu \mathrm{gC} / \mathrm{min}$ to keep the pressure constant inside the syringe (filled to $1300 \mathrm{mbar}$ ), allowing the ion source to produce stable currents.

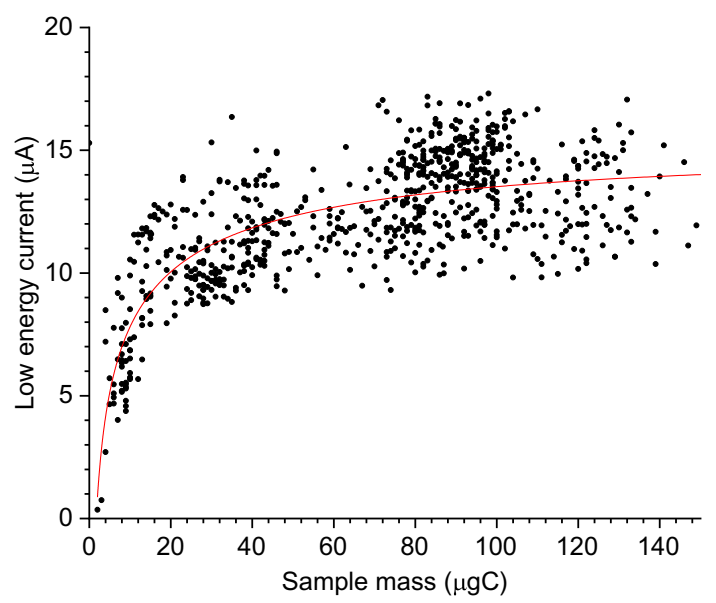

Fig. 1. Low energy current dependence on the injected mass of about $800 \mathrm{CO}_{2}$ samples measured over the last year using the CHS and the EA devices connected to the GIS.
The tuning of AixMICADAS in gas configuration begins by loading the last optical parameters of the instrument used to measure solid targets. When the cesium temperature is sufficiently high and stable, an OxA2 standard sample from the $\mathrm{CO}_{2}$ gas cylinder is injected to perform small adjustments of the optical elements at the low energy side and especially inside the ion source to maximize beam currents and ion transmission. The optimization process in gas configuration takes no more than 15 min which can be done with a fully filled syringe.

Fig. 1 shows a compilation over one year of the average low energy ion current as a function of sample mass. The current increases quickly with the sample size up to $20 \mu \mathrm{gC}$, stabilizing between 10 and $15 \mu \mathrm{A}$ for samples $>20 \mu \mathrm{gC}$. The large scatter of ion currents for samples of the same mass is still poorly understood and may be related to variations introduced by the sputtering process and the variations of the pressure inside the syringe and deviations of the $\mathrm{CO}_{2}$-He proportions from their optimal values (1300 mbar and $5 \% \mathrm{CO}_{2}$, respectively). The overall system can be operated in a fully automated way for samples larger than $10 \mu \mathrm{gC}$, since $\mathrm{LE}{ }^{12} \mathrm{C}^{-}$currents can be maintained above $10 \mu \mathrm{A}$ for 4-15 min. Measuring smaller samples is more difficult as they need to be manually controlled to guarantee the proper onset of the ion current and an efficient acquisition process of the data during the few minutes of stable currents $>3 \mu \mathrm{A}$ (e.g. Fig. 2 left panel).

Even if the gas targets are baked at $350{ }^{\circ} \mathrm{C}$ for $2 \mathrm{~h}$ before being placed in the 40 position magazine, a pre-sputtering process of each new target is performed for about a minute to achieve the complete cleaning of the titanium insert inside the target (until the ${ }^{12} \mathrm{C}^{-}$ion current becomes $<110 \mathrm{nA}$ ). The $\mathrm{CO}_{2}$ of the sample is then pushed inside the capillary connected to the hollow target and the ${ }^{12} \mathrm{C}^{-}$ion current takes about $100 \mathrm{~s}$ to stabilize.

Our standard protocol in gas configuration consists of starting the measurement with two OxA2 standards from the gas cylinder for about ten minutes each (30,000 counts per target). Blank samples are measured after a purge of the system using the blank gas cylinder, which allows to reach operational level for real blank sample measurement (when $\mathrm{F}^{14} \mathrm{C}<4 \%$ ). Each gas measurement sequence ends with the analysis of one or two OxA2 samples from the gas cylinder to ensure a proper normalization of all samples.

In gas configuration, the ionization efficiency (number of ${ }^{12} \mathrm{C}^{-}$ions divided by the total number of $\mathrm{CO}_{2}$ molecules in the sample) ranges between $2 \%$ and $5 \%$, based on 17 samples with sample sizes between $3 \mu \mathrm{gC}$ and $55 \mu \mathrm{gC}$. Similar efficiencies have been measured on other MICADAS systems [7,13,14].

As typical examples, Fig. 2 shows the ${ }^{12} \mathrm{C}^{+}$current and the raw isotope ratios ${ }^{14} \mathrm{C} /{ }^{12} \mathrm{C}$ and ${ }^{13} \mathrm{C} /{ }^{12} \mathrm{C}$ recorded during the measurements of a $6 \mu \mathrm{gC}$ sample and a $117 \mu \mathrm{gC}$ sample produced with the CHS device.

For the large sample (Fig. 2 right panel), data cycles recorded before the current stabilization are removed and the measurement is manually stopped after $12 \mathrm{~min}$ before the degradation of the Ti target.

For the typical small sample shown in Fig. 2 left panel, all data points before the stabilization of the current and after its fall are discarded in the final measurement evaluation and calculation. In this case, the measurement time is limited only by the low mass of the sample and the $\mathrm{CO}_{2}$ is entirely consumed and ionized in optimal conditions with a single target. In the example shown in Fig. 2 , the $\mathrm{F}^{14} \mathrm{C}$ values of both samples are in agreement: $\mathrm{F}^{14} \mathrm{C}_{6 \mu \mathrm{gC}}=1.123 \pm 0.020$ and $\mathrm{F}^{14} \mathrm{C}_{117 \mu g \mathrm{C}}=1.103 \pm 0.009$.

In fact, only about a third of the large sample $(\approx 30 \mu \mathrm{gC})$ was consumed during the $12 \mathrm{~min}$ analysis shown in Fig. 2. When the sample is large enough (i.e. $>60 \mu \mathrm{gC}$ ), it is also possible to measure the remaining $\mathrm{CO}_{2}$ with a second or even a third Ti target in order to improve the overall precision. For instance, the measurement of three replicates of sample Aix-10339 on one target give ${ }^{14} \mathrm{C}$ ages of $11,890 \pm 110$ years BP, $11,815 \pm 107$ years BP and 11,809 \pm 108 years BP. The measurement of the same sample material on three targets gives a ${ }^{14} \mathrm{C}$ age with an improved precision of $11,940 \pm 70$ years BP. 

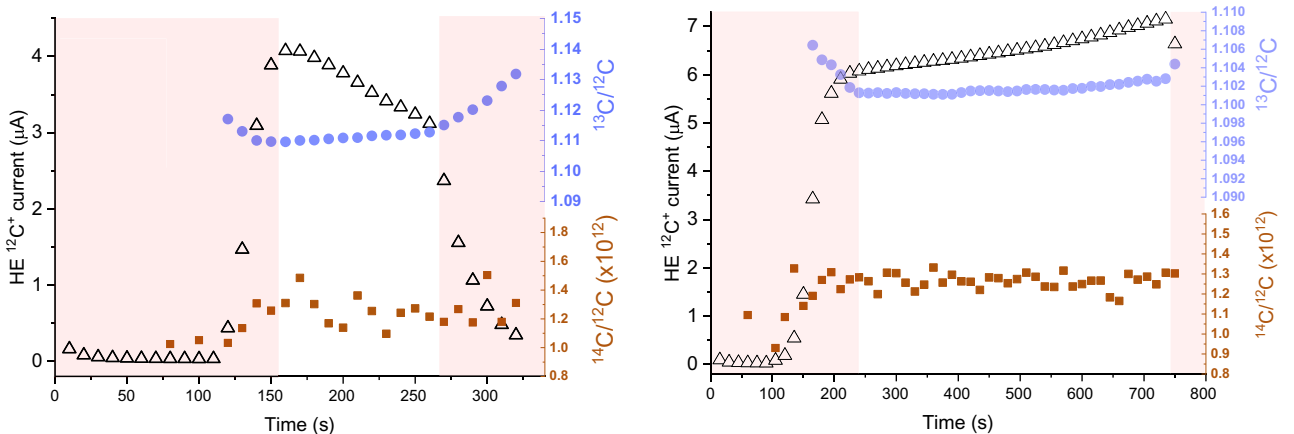

Fig. 2. Data acquisition sequence of a $6 \mu \mathrm{gC}$ and a $117 \mu \mathrm{gC}$ mass samples. ${ }^{12} \mathrm{C}^{+}$current (white triangles) and raw isotope ratios ${ }^{14} \mathrm{C} /{ }^{12} \mathrm{C}$ (brown squares) and ${ }^{13} \mathrm{C} /{ }^{12} \mathrm{C}$ (blue dots) recorded during injection time. Shaded areas represent the discarded data in the measurement sequence. (For interpretation of the references to colour in this figure legend, the reader is referred to the web version of this article.)

\section{Contamination effects}

The memory effect of one sample onto the next is an issue which is particularly significant when the $\mathrm{F}^{14} \mathrm{C}$ of both samples are different. Even if a trap cleaning procedure is always applied between samples (heating to $450{ }^{\circ} \mathrm{C}$ and flushing with helium for a minute), a very small proportion of the sample still remains inside the zeolite trap. Nevertheless, the zeolite trap is probably not the only source of the memory effect. There may be additional $\mathrm{CO}_{2}$ adsorption in other parts of the system: capillaries, EA tubes, or water traps, for instance.

Fig. 3 left panel shows a measurement sequence of modern samples (OxA2; Aix-10000.9) directly followed by the measurement of blank samples (Phthalic anhydride; Aix-10109.2) combusted inside the EA device. Fig. 3 right panel shows an equivalent measurement sequence with carbonates using the CHS device with a modern coral sample (Porites from Moorea, Aix-10327.2) and IAEA-C1 reference material as a blank sample (Aix-10342.1). In both cases, one sample measurement is enough to suppress the memory effect, which is equivalent to $4 \%$ for the EA + GIS (compatible with the value observed in [13]) and $3 \%$ with the GIS + CHS. This memory effect is larger than the values of $1.5 \%$ and 1.0\% measured for mg-size samples with the graphitization system AGE3 connected to the EA and the CHS, respectively. The difference may be linked to the GIS characterized by additional complex surfaces and valves.

To limit or totally suppress the memory effect, three possibilities can be chosen during gas measurement sessions. The first alternative is to inject the $\mathrm{CO}_{2}$ from the same sample into the zeolite trap, release it inside the syringe and purge the syringe without measuring the sample. This procedure requires that enough material is available and that it not too precious to afford losing half of it. The second way is to measure samples with similar ages in sequence. This requires some a priori knowledge on ages, which is often the case. For example, in sediment cores, carbonate samples can be measured following the stratigraphy, from bottom to top. The third possibility is to correct the activity of the contaminated sample from the previous one by using the memory effect values determined with modern and blank samples.

In addition to the memory effect, the contribution of background contamination exists and must be taken into account when the size of the sample is small. There is no clear identification of the origin of this contamination. It may come from microparticles suspended in ambient air (aerosols), from the various gases used in EA, CHS and GIS, or from any other material used in the laboratory.

As an approximation, this background contamination is assumed to be constant in terms of mass and $\mathrm{F}^{14} \mathrm{C}$ ratio. It is evaluated by measuring two sets of samples: the first one includes ${ }^{14} \mathrm{C}$ free samples and the second one includes modern samples. Both sets are measured for a mass range between $3 \mu \mathrm{gC}$ and $100 \mu \mathrm{gC}$. Fig. 4 shows the measured $\mathrm{F}^{14} \mathrm{C}$ of the IAEA-C1 blank sample and of modern coral (Porites from Moorea) for different masses combusted in the EA coupled to the GIS. A least squares procedure is used to compute the optimized couple of values for the mass $\mathrm{M}_{\mathrm{c}}$ and the $\mathrm{F}^{14} \mathrm{C}_{\mathrm{c}}$ of the contaminant (in the computation the mass is free to spread between $0 \mu \mathrm{gC}$ and $20 \mu \mathrm{gC}$ and the $\mathrm{F}^{14} \mathrm{C}_{\mathrm{c}}$ between 0 and 1.7).

Table 2 shows that the calculated $\mathrm{F}^{14} \mathrm{C}_{\mathrm{c}}$ of the residual contaminant is about the same for all devices, even for the graphitized samples prepared with the AGE3 system. This contamination activity is very low compared to that evaluated in other ${ }^{14} \mathrm{C}$ laboratories $[13,15,16]$ and to values previously extracted from our aerosol measurements using the EA coupled to the GIS $\left(\mathrm{F}^{14} \mathrm{C}_{\mathrm{c}}=0.73\right.$ and $\left.\mathrm{M}_{\mathrm{c}}=1.45 \mu \mathrm{g}\right)$ [12]. The difference with our previous evaluation comes from the fact that the measurement of aerosols requires the use of much larger $\mathrm{Ag}$ boats (ie $240 \mathrm{mg}$ ). This can lead to contamination over and above that determined in Table 2 with small Ag boats for the EA + GIS configuration. Further tests on samples with intermediate activities are still needed to confirm the low activity measured for this constant contamination.

\section{Results and performances}

\subsection{Standard samples}

All measurements are normalized with the OxA2 (NIST 4990C) samples from the gas cylinder connected to the GIS. Fig. 5 shows 132 OxA2 samples with a mass of about $100 \mu \mathrm{gC}$ measured during the last 2.5 years. Each data point corresponds to a measurement time of about $12 \mathrm{~min}$ on a single target to reach a counting statistic of around $30,000{ }^{14} \mathrm{C}^{+}$counts. In order to evaluate the level of precision and accuracy of the GIS-AMS instrument, all these individual OxA2 measurements are not used for the normalization calculation and are considered as unknown samples.
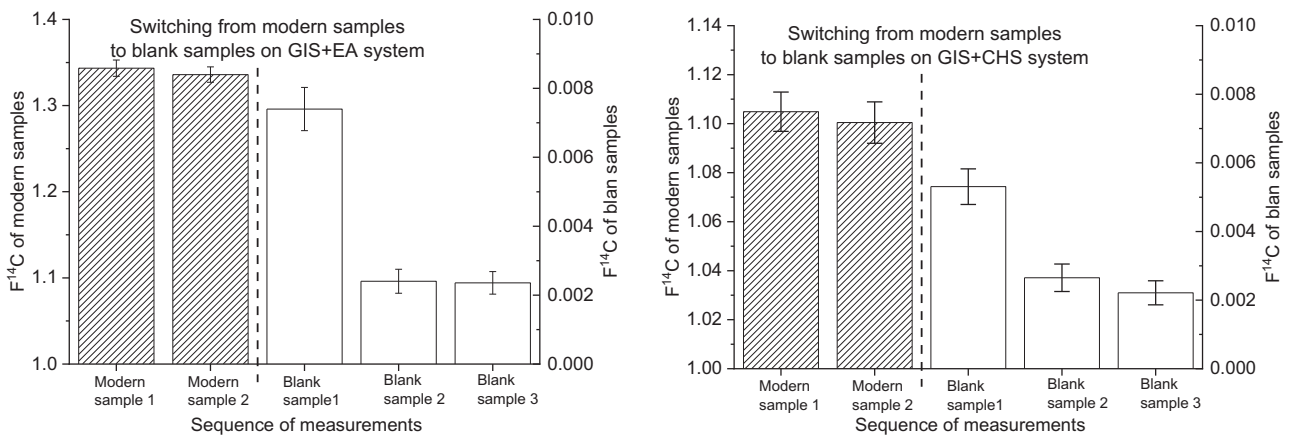

Fig. 3. Two figures showing the $\mathrm{F}^{14} \mathrm{C}$ of modern samples (dashed bars) and raw blank samples (blank bars) measured in a direct sequence to estimate the cross contamination effect induced by the GIS + EA on the left and GIS + CHS on the right. The memory effect is evaluated at $4 \%$ for the GIS + EA configuration and $3 \%$ for the GIS + CHS configuration. 


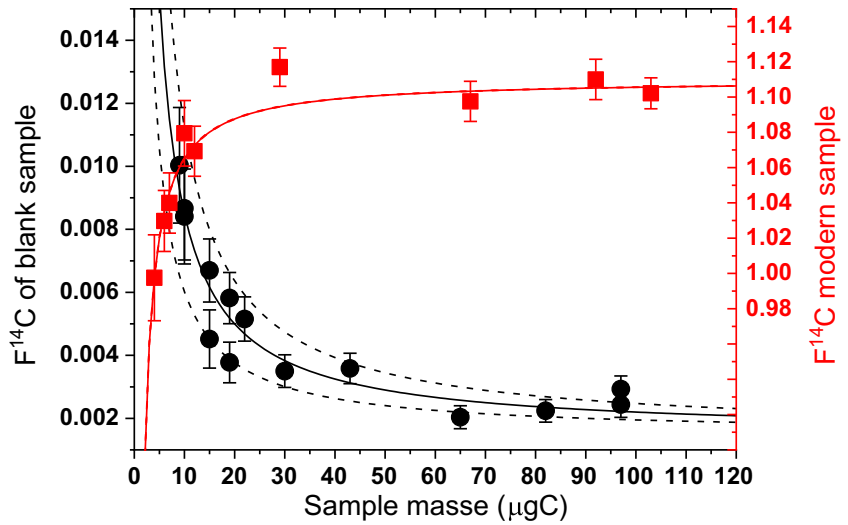

Fig. 4. $\mathrm{F}^{14} \mathrm{C}$ of IAEA-C1 blank sample (black dots) and modern sample Moorea porites (red squares) for different masses of sample measured on the EA + GIS system. Solid lines and dashed lines represent the least squares fit model with its $95 \%$ confidence interval with a constant contamination. (For interpretation of the references to colour in this figure legend, the reader is referred to the web version of this article.)

Table 2

Evaluation of $\mathrm{F}^{14} \mathrm{C}$ and mass of the constant contamination for the EA and CHS coupled to the GIS and for the CHS coupled to the AGE3 system for graphite target production. Values are calculated using a weighted nonlinear least squares model.

\begin{tabular}{lll}
\hline System used & $\mathrm{M}_{\mathrm{c}}(\mu \mathrm{gC})$ & $\mathrm{F}^{14} \mathrm{C}_{\mathrm{c}}$ \\
\hline GIS + EA & $0.55 \pm 0.05$ & $0.12 \pm 0.03$ \\
GIS + CHS & $0.18 \pm 0.02$ & $0.14 \pm 0.02$ \\
AGE + CHS & $1.74 \pm 0.42$ & $0.14 \pm 0.05$ \\
\hline
\end{tabular}

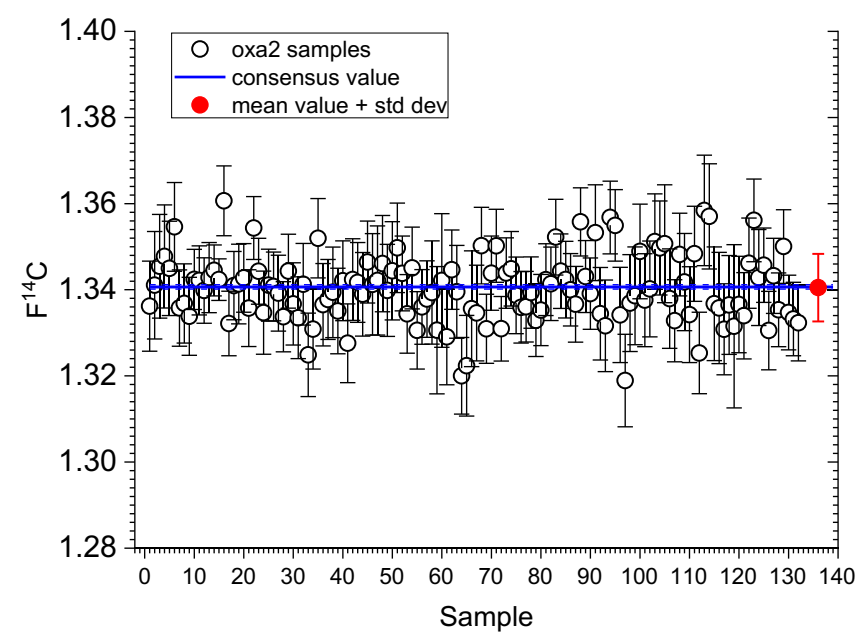

Fig. 5. $\mathrm{F}^{14} \mathrm{C}$ values of 132 oxalic 2 standard material considered as unknown gas samples. The red dot shows the weighted mean value and its associated standard deviation of $7.8 \%$. White circles represent the measured $\mathrm{F}^{14} \mathrm{C}$ of each OxA2 sample. The blue line represents the reference value with its associated error [17].

Statistical analysis of the data gives an average $\mathrm{F}^{14} \mathrm{C}$ of 1.3403 and a standard deviation (SD) of 0.0078 (i.e. 6\%o). This arithmetic mean and its associated error (std err $=0.0007$ ) are compatible with the weighted mean (1.3405) and the weighted error (0.0008), and closely agree with the reference value of $1.3407 \pm 0.0005$ [17]

The scatter value $(6 \%)$ probably overestimates the true operational dispersion because the number of OxA2 samples is limited during a gas measurement session and the first OxA2 (used for normalization) is also the first sample measured during a day-session, and might thus exhibit extra variability. We can estimate from these measurements the contribution of an external error of roughly 4\%, which is an indication of the system stability through time. This error is evaluated as the additional contribution to the error coming from pure counting statistics to describe the observed long term scattering of the data ( $\sigma_{\text {long }}$ term $^{2}=\sigma_{\text {stat }}^{2}+\sigma_{\text {external }}^{2}$ ).

In addition, the precision of AixMICADAS is assessed by measuring small samples of a modern coral sample (Porites from Moorea (Aix10327), while accuracy and precision are also evaluated with a halfmodern carbonate sample from the reference material IAEA-C2 (Aix10346). Following our standard pretreatment protocol (see the companion paper by [21]), the measured $\mathrm{F}^{14} \mathrm{C}$ value for the modern coral is 1.1105 with a standard deviation of 0.0089 (i.e. $8 \%$ ) for 18 measured samples with a mass larger than $80 \mu \mathrm{gC}$. The standard deviation for aliquots of the modern coral sample is thus about $2 \%$ larger than that measured in OxA2 samples. This additional scatter may be linked to the chemistry treatment applied to the carbonate samples, and possibly to heterogeneities among the coral subsamples.

The 23 IAEA-C2 samples give a $\mathrm{F}^{14} \mathrm{C}$ value of 0.4086 with a SD of 0.0031 and a stderr of 0.0006 , which are close to the consensus value of $0.4114 \pm 0.0003$ [18]. The measured SD is equivalent to $8 \%$, which is compatible with that of modern coral. Taken at face value, the results indicate a small difference of 0.0028 between the measured $\mathrm{F}^{14} \mathrm{C}$ value and the consensus value for the IAEA-C2 standard. This small difference may come from the leaching process, as we also find the same difference between untreated and leached samples measured for solid graphite targets: mean $\mathrm{F}^{14} \mathrm{C}=0.4121, \mathrm{SD}=0.0035, \mathrm{n}=7$ and 0.4093 , $\mathrm{SD}=0.0024, \mathrm{n}=10$, respectively (see companion paper by [21]).

\subsection{Blank samples}

Table 3 shows the ${ }^{14} \mathrm{C}$ blanks and the $\delta^{13} \mathrm{C}$ measured with AixMICADAS on small samples processed with the different devices connected to the GIS. All samples presented in Table 3 are large enough to avoid the constant contamination effect. Blanks $(\mathrm{n}=129)$ from the $\mathrm{CO}_{2}$ bottle (Linde Gas) are measured at least once for every gas sample magazine primarily to purge the system before measuring the procedural blanks that represent the different sample types and secondly to check that the system is ready to measure ${ }^{14} \mathrm{C}$ free $\mathrm{CO}_{2}$ samples. The second set of blanks (i.e. processing blanks) is the one used to correct the ${ }^{14} \mathrm{C}$ results of unknown samples. Usually two $\mathrm{CO}_{2}$ bottle blank samples are measured at the beginning of a gas session before the procedural blanks. In Table 3 , the mean value of the $\mathrm{CO}_{2}$ blanks bottle is based on the second blank measurement (and more if available in the particular magazine). This mean value reflects the starting level just before the measurement of processing blanks.

The IAEA-C1 calcite is our reference blank for measurements with the CHS coupled to the GIS. It shows a very low $\mathrm{F}^{14} \mathrm{C}$ value of 0.0014 , $\mathrm{SD}=0.0004, \mathrm{n}=51$, equivalent to a ${ }^{14} \mathrm{C}$ age of 52,800 years $\mathrm{BP}$, $\mathrm{SD}=2300$ years BP. A similar blank level is measured on the SIRI-K calcite, which agrees with results reported in the frame of the SIRI intercomparison program.

Different organic materials have been used with the EA coupled to the GIS. VIRI-K is our reference blank for wood measurement, phthalic

Table 3

Mean values of $\mathrm{F}^{14} \mathrm{C}$ and $\delta^{13} \mathrm{C}$ with the associated standard deviation measured for $\mathrm{N}$ blank samples measured on the GIS interface.

\begin{tabular}{llllll}
\hline Blank (device) & $\mathrm{F}^{14} \mathrm{C}$ & Std. dev. & $\delta{ }^{13} \mathrm{C}(\%)$ & Std. dev & $\mathrm{N}$ \\
\hline $\mathrm{CO}_{2}$ LindeGas (bottle) & 0.0028 & 0.0011 & -3.9 & 1.9 & 129 \\
$\begin{array}{l}\text { IAEA-C1 (CHS) } \\
\text { Iceland doublespar SIRI-K }\end{array}$ & 0.0014 & 0.0004 & -0.2 & 1.1 & 51 \\
$\quad$ (CHS) & 0.0016 & 0.0005 & -10.1 & 2.4 & 5 \\
VIRI-K (EA) & & & & & \\
$\mathrm{C}_{16} \mathrm{H}_{32} \mathrm{O}$ (EA) & 0.0027 & 0.0010 & -21.6 & 1.2 & 7 \\
Phthalic acid anhydride (EA) & 0.0026 & 0.0005 & -44.4 & 0.6 & 8 \\
\end{tabular}


anhydride acid (from Merck) is used to control the blank of graphite production and the $\mathrm{C}_{16} \mathrm{H}_{32} \mathrm{O}$ ketone (from Fluka) is a standard molecular compound used in HPLC extraction. The three samples show a similar $\mathrm{F}^{14} \mathrm{C}$ level below 0.003 , equivalent to a ${ }^{14} \mathrm{C}$ age of 47800 years $\mathrm{BP}$.

For a particular gas measurement session, typically lasting a full day, a background estimation is used to correct the raw results for unknown samples. This background is the average value of representative blanks measured during the same session. As a conservative measure, a variability of $\pm 30 \%$ around this background value is propagated in the final error bar of the unknown sample (to take into account the long term variability of blanks). In rare cases of blank variability greater than $\pm 30 \%$ during a particular session, the measured variability during the session is used instead for error propagation.

\section{3. ${ }^{13} \mathrm{C} /{ }^{12} \mathrm{C}$ ratios and fractionation correction}

The sequential injection of the three isotopes allows AixMICADAS to measure the ${ }^{13} \mathrm{C} /{ }^{12} \mathrm{C}$ ratio, which is needed to correct ${ }^{14} \mathrm{C}$ measurements for fractionation effects using BATS software [9]. For OxA2 samples from the standard $\mathrm{CO}_{2}$ bottle that are considered as unknown samples, a mean $\delta^{13} \mathrm{C}$ value of $-18.0 \%$ with an SD of $1.8 \%$ is calculated based on 132 measurements (leading to a standard error of $0.2 \%$ ). These gas data agree with our measurements on OxA2 solid targets considered as unknown: mean $\delta^{13} \mathrm{C}$ of $-17.5 \%$ with a SD of $1.0 \%$ based on 150 analyses (leading to a standard error of $0.08 \%$ ). Both $\delta^{13} \mathrm{C}$ averages measured with AixMICADAS agree with the reference value of $(-17.8 \pm 0.1) \%$ [19] and the direct IRMS measurement provided for the $\mathrm{CO}_{2}$ bottle $(-17.2 \%)$.

By contrast, the $\delta^{13} \mathrm{C}$ of IAEA-C2 based on the gas measurement of 23 samples through the CHS-GIS interface is $-10.4 \%$ with a SD of $0.8 \%$, which is about $2 \%$ lower than the consensus value $(-8.25 \pm 0.31 \% 0[18])$.

Similarly, the $\delta^{13} \mathrm{C}$ values measured for the different blank samples through the EA + GIS or CHS + GIS exhibit a negative shift of around $-2 \%$ when compared to precise and accurate results on solid graphite targets. For IAEA-C1, we obtained a mean $\delta^{13} \mathrm{C}$ of $2.5 \%$ with a SD of $2.2 \%$ on graphite targets, based on 22 analyses (leading to a standard error of $0.5 \%$ ). This mean value is compatible with the reference value of $2.42 \pm 0.33 \%$ [18], in contrast to gas samples that are shifted by $-2.5 \%$ (Table 3). A similar bias is observed on the $\delta^{13} \mathrm{C}$ of VIRI-K and Phthalic acid anhydride which provided the following averages with graphite targets: respectively, $-20.2 \%$ with a SD of $1.1 \%$ based on 64 analyses and $-29.0 \%$ with a SD of $1.9 \%$ based on 27 analyses.

Collectively, our observation seems to point towards an additional isotopic fractionation linked to the zeolite trap system within the GIS or to a similar fractionation for both EA and CHS systems. Indeed, these steps are not included in the measurements of $\mathrm{CO}_{2}$ bottle, which lead to $\delta^{13} \mathrm{C}$ in agreement with expectations.

\section{Conclusion}

The performances of AixMICADAS for the measurement of small $\mathrm{CO}_{2}$ gas samples have been evaluated over the last three years. Modern samples can be measured with a precision of $7 \%$ in a run of $12 \mathrm{~min}$ with stable ${ }^{12} \mathrm{C}^{-}$ion current typically on the order of $10-15 \mu \mathrm{A}$. An additional scattering of about $4 \%$ has been evaluated from the longterm measurements of modern standards.

Detailed work has been performed to suppress contamination effects for both carbonate and organic material and to survey the residual background for samples ranging between 10 and $100 \mu \mathrm{gC}$. These developments allow to date material over the full 50-kyr dating range of ${ }^{14} \mathrm{C}$ and have enabled us to date ancient collagen [20] and analyze atmospheric aerosols [12]. Ongoing work on dating different fractions of aerosols, purified organic compounds and ${ }^{14} \mathrm{C}$ formed in situ will incite us to perform more tests with the closed ampoule cracker.

We also plan to dedicate more research to improving understanding of the isotopic fractionation problem, notably by measuring OxA2 samples through the EA + GIS system and the cracker to better evaluate the GIS component. Even if natural and procedural isotopic fractionations need to be corrected for in the $\mathrm{F}^{14} \mathrm{C}$ normalization procedure, we will continue to monitor and compare ${ }^{14} \mathrm{C}$ and ${ }^{13} \mathrm{C}$ results on the same samples measured with gas and solid targets. With the goal of using similar protocols for standard and unknown samples, we will also test normalization based on OxA2 samples measured through the EA + GIS. A comparable procedure will be used for the CHS + GIS by using a modern carbonate in-house standard.

\section{Acknowledgements}

AixMICADAS was acquired and is operated in the framework of the EQUIPEX project ASTER-CEREGE with additional matching funds from the Collège de France and the ANR project CARBOTRYDH.

\section{References}

[1] E. Bard, T. Tuna, Y. Fagault, L. Bonvalot, L. Wacker, S. Fahrni, H.-A. Synal, AixMICADAS the accelerator mass spectrometer dedicated to $14 \mathrm{C}$ recently installed in Aix-en-Provence, France, Nucl. Instr. Meth. Phys. Res. Sect. B Beam Interact. Mater. At. 361 (2015) 80-86, https://doi.org/10.1016/j.nimb.2015.01.075.

[2] L. Wacker, S.M. Fahrni, I. Hajdas, M. Molnar, H.-A. Synal, S. Szidat, Y.L. Zhang, A versatile gas interface for routine radiocarbon analysis with a gas ion source, Nucl. Instr. Meth. Phys. Res. Sect. B Beam Interact. Mater. At. 294 (2013) 315-319, https://doi.org/ 10.1016/j.nimb.2012.02.009.

[3] M. Stuiver, H.A. Polach, Discussion reporting of 14 C data, Radiocarbon 19 (1977) 355-363.

[4] P.J. Reimer, T.A. Brown, R.W. Reimer, Discussion: reporting and calibration of post-bomb 14C data, Radiocarbon 46 (2004) 1299-1304, https://doi.org/10.1017/ S0033822200033154.

[5] H.-A. Synal, M. Stocker, M. Suter, MICADAS: a new compact radiocarbon AMS system, Nucl. Instr. Meth. Phys. Res. Sect. B Beam Interact. Mater. At. 259 (2007) 7-13, https:// doi.org/10.1016/j.nimb.2007.01.138

[6] L. Wacker, G. Bonani, M. Friedrich, I. Hajdas, B. Kromer, M. Nemec, M. Ruff, M. Suter, H.A. Synal, C. Vockenhuber, MICADAS: routine and high-precision radiocarbon dating, Radiocarbon 52 (2010) 252.

[7] S.M. Fahrni, L. Wacker, H.-A. Synal, S. Szidat, Improving a gas ion source for 14C AMS, Nucl. Instr. Meth. Phys. Res. Sect. B Beam Interact. Mater. At. 294 (2013) 320-327, https://doi.org/10.1016/j.nimb.2012.03.037.

[8] A.M. Müller, M. Döbeli, M. Suter, H.-A. Synal, Performance of the ETH gas ionization chamber at low energy, Nucl. Instr. Meth. Phys. Res. Sect. B Beam Interact. Mater. At. 287 (2012) 94-102, https://doi.org/10.1016/j.nimb.2012.06.012.

[9] L. Wacker, M. Christl, H.-A. Synal, Bats: a new tool for AMS data reduction, Nucl. Instr. Meth. Phys. Res. Sect. B Beam Interact. Mater. At. 268 (2010) 976-979, https://doi.org/ 10.1016/j.nimb.2009.10.078.

[10] M. Ruff, S. Fahrni, H.W. Gaggeler, I. Hajdas, M. Suter, H.-A. Synal, S. Szidat, L. Wacker, On-line radiocarbon measurements of small samples using elemental analyzer and MICADAS gas ion source, Radiocarbon 52 (2011) 1645-1656.

[11] L. Wacker, R.-H. Fülöp, I. Hajdas, M. Molnár, J. Rethemeyer, A novel approach to process carbonate samples for radiocarbon measurements with helium carrier gas, Nucl. Instr. Meth. Phys. Res. Sect. B Beam Interact. Mater. At. 294 (2013) 214-217, https://doi.org/ 10.1016/j.nimb.2012.08.030.

[12] L. Bonvalot, T. Tuna, Y. Fagault, J.-L. Jaffrezo, V. Jacob, F. Chevrier, E. Bard, Estimating contributions from biomass burning, fossil fuel combustion, and biogenic carbon to carbonaceous aerosols in the Valley of Chamonix: a dual approach based on radiocarbon and levoglucosan, Atmos. Chem. Phys. 16 (2016) 13753-13772, https://doi.org/10.5194/ acp-16-13753-2016.

[13] M. Ruff, S. Szidat, H.W. Gäggeler, M. Suter, H.-A. Synal, L. Wacker, Gaseous radiocarbon measurements of small samples, Nucl. Instr. Meth. Phys. Res. Sect. B Beam Interact. Mater. At. 268 (2010) 790-794, https://doi.org/10.1016/j.nimb.2009.10.032.

[14] H. Hoffmann, R. Friedrich, B. Kromer, S. Fahrni, Status report: implementation of gas measurements at the MAMS 14C AMS facility in Mannheim, Germany, Nucl. Instr. Meth. Phys. Res. Sect. B Beam Interact. Mater. At. 410 (2017) 184-187, https://doi.org/10. 1016/j.nimb.2017.08.018.

[15] Q. Hua, U. Zoppi, A.A. Williams, A.M. Smith, Small-mass AMS radiocarbon analysis at ANTARES, Nucl. Instr. Meth. Phys. Res. Sect. B Beam Interact. Mater. At. 223-224 (2004) 284-292, https://doi.org/10.1016/j.nimb.2004.04.057.

[16] M. Salehpour, K. Håkansson, G. Possnert, Small sample Accelerator Mass Spectrometry for biomedical applications, Nucl. Instr. Meth. Phys. Res. Sect. B Beam Interact. Mater. At. 361 (2015) 43-47, https://doi.org/10.1016/j.nimb.2015.04.047.

[17] M. Stuiver, International agreements and the use of the new oxalic acid standard, Radiocarbon 25 (1983) 793-795.

[18] B. Kromer, J. Van der Plicht, The IAEA 14C intercomparison exercise 1990, Radiocarbon 34 (1992) 506-519.

[19] Wb. Mann, An international reference material for radiocarbon dating, Radiocarbon 25 (1983) 519-527.

[20] H. Fewlass, S. Talamo, T. Tuna, Y. Fagault, B. Kromer, H. Hoffmann, C. Pangrazzi, J.J. Hublin, E. Bard, Size matters: radiocarbon dates of $<200 \mu \mathrm{g}$ ancient collagen samples with AixMICADAS and its gas ion source, Radiocarbon (2017) 1-15, https://doi.org/10 1017/RDC.2017.98.

[21] Y. Fagault, T. Tuna, F. Rostek, E. Bard, Radiocarbon dating small carbonate samples with the gas ion source of AixMICADAS, (2017) (this issue). 